The Strange Persistence of the IS/LM Model

by

David Colander

October 2003

MIDDLEBURY COLLEGE ECONOMICS DISCUSSION PAPER NO. 03-31

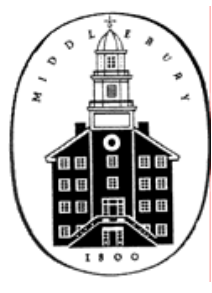

DEPARTMENT OF ECONOMICS

MIDDLEBURY COLLEGE

MIDDLEBURY, VERMONT 05753

http://www.middlebury.edu/ econ 


\title{
The Strange Persistence of the IS/LM Model
}

\author{
David Colander \\ Department of Economics \\ Middlebury College \\ Middlebury, Vermont 05753 \\ Colander@Middlebury.edu \\ Phone: 802-443-5302 \\ Fax: 802-443-2084
}

Paper prepared for presentation at the April 25-27, 2003, Hope Conference on "The IS/LM Model: Its Rise, Fall, and Strange Persistence" at Duke University 


\section{The Strange Persistence of the IS/LM Model}

\section{David Colander}

Why has the IS/LM model persisted? In this paper I consider that question, along with the related, and in some ways more interesting, question of how the use of the IS/LM model has changed over time. I begin by discussing some general issues about the persistence of IS/LM and how its treatment has changed, presenting some bibliometric evidence about the appearance of IS/LM in the literature over the last forty years. Then I look specifically at how the treatment of IS/LM has evolved from the 1960s until today, comparing a 1960s intermediate macro text with a modern intermediate text. Finally, I relate that discussion to some thoughts about the future of the IS/LM model.

\section{Some General Comments on the Persistence of IS/LM}

IS/LM analysis is a creature of pedagogy, and to understand its persistence one must understand the nature of economic pedagogy in the intermediate macro course, where the IS/LM model predominates. Since just about every economics student takes intermediate macro, just about every economist has taken intermediate macro, so as long as IS/LM continues to be used in that intermediate macro course, IS/LM will retain its central role in rough and ready discussions of macro policy. IS/LM provides a common framework (the "trained intuition") that economists can use to discuss macro policy, as suggested by Tobin (1980), Solow (1984), and others.

To say that the IS/LM model has persisted is not to say that its use has remained the same, or that it currently plays a central role in advanced discussions of macroeconomic policy and theory. In the 1960s it did play a significant role in both theoretical and empirical discussions of macro, but that is no longer true, which means that the way in which the model is used has changed considerably over the last 40 or 50 years. Today IS/LM has a very limited range of applicability. For example, it does not appear in the principles texts, whereas back in the 1960s it could be found in some highlevel principles texts and in appendices to others. Even the AE/AP building block of the IS/LM model is disappearing from the intro texts and is being replaced with the AS/AD model. ${ }^{1}$

Another example of its limited range is that modern theoretical debates in top journals make little reference to the IS/LM model. For example, in the recently published two-volume Handbook of Macroeconomics (1999) the term IS/LM is hardly mentioned and no discussion of policy or theoretical issues is centered on it. Similarly, other than sometimes being referenced in a review of intermediate macro, graduate courses in macro

\footnotetext{
${ }^{1} \mathrm{An}$ interesting aspect of this development is that, technically, the AS/AD model is derivative of the IS/LM model. Earlier, the AE/AP multiplier model, a building block for IS/LM, dominated the principles texts, and thus the IS/LM intermediate macro model was an extension of the model learned in principles. Today, the multiplier model is absent from many principles books, and AS/AD analysis has become a self-standing analysis.
} 


\section{The Strange Persistence of IS/LM}

seldom mention this model. ${ }^{2}$ There are attempts to translate modern work into the IS/LM framework, such as we see in the work of Yun (1996) or Clarida, Gali, and Gertler (1999). But the foundation of their models is in dynamic general equilibrium theory, and the translation into IS/LM is not central to their analysis. The translation is done simply to give policy-oriented economists a way of relating their conclusions to an IS/LM framework. It is the underlying dynamic general equilibrium model, and not the translation of that debate into the IS/LM model, that is central to modern theoretical debates $^{3}$

The current situation is in marked contrast to the 1960s when both policy debates and theoretical debates were centered on the IS/LM model. In the 1960s what one learned in intermediate macro provided a foundation for what one learned in upper level and graduate courses. IS/LM was the end of the line - providing a synthesis of the Keynesian and Classical models, which were central to the policy debates and higher theoretical work in economics. Since one learned IS/LM in the intermediate course there was no quantum jump between intermediate and advanced work in macro. For example, in 1965 Duncan Foley, based on a senior seminar in macro he did at Swarthmore, exempted out of the graduate macro course at Yale. (Foley 2002)

As late as the mid 1970s IS/LM remained the foundation of the graduate course. For example, in my first graduate course in macro in 1971, we had a new Stanford graduate as a professor under whom we studied matrix IS/LM models where significant disaggregation was allowed, but the IS/LM structure was maintained. So IS/LM was still the core structure being taught. Today that has changed; the discussion of the multimarket goods and money market equilibria gets far less emphasis, and instead IS/LM is used for little else than a handy framework for discussing policy. So IS/LM has persisted, but its role has changed substantially.

In the 1960s, the IS/LM model not only was a stepping stone to theoretical macro, it was also a stepping stone to empirical macro and the large econometric models that were then the center of advanced macroeconomic forecasting and policy analysis. When students learned IS/LM in the 1960s they were learning a very simple example of the much larger econometric models, which had thousands, rather than tens, of equations, but otherwise had the same structure. Lawrence Klein (2000) nicely presents this pedagogical use of IS/LM and shows how IS/LM would be presented and given empirical content, if it still played that role. He suggests that "systems that are carefully fitted to observed data and capable of generating realistic values are far better for teaching purposes." (p. 158). This is, of course, true, but that is not the way IS/LM is generally taught today, in part

\footnotetext{
${ }^{2}$ At Princeton, for instance, it does not appear in recent graduate macro syllabi. At Harvard, the professor who provided the overview told me he lectured it on briefly, but otherwise it went unmentioned. Informal discussion with professors at other schools suggests that this is the rule at top schools.

${ }^{3}$ In their work they show that in these dynamic general equilibrium models, given assumptions of nominal rigidities, it is possible to derive a temporary negative relationship between output and interest rates that can be called an "IS" curve. They close the model not with a traditional LM curve, but instead with a specification of nominal interest rates, but that distinction is, in my view a minor one and can be related to the standard IS/LM model by defining an effective LM curve that incorporates a monetary feedback rule. See Colander and Gamber (2002).
} 


\section{The Strange Persistence of IS/LM}

because the profession is far more suspicious of large-scale econometric models and the information that can be drawn from them. So IS/LM is still taught but it is not taught as a theoretical or empirical stepping stone as it was in the 1960s and early 1970 s.

\section{Bibliometric Evidence}

To shed light on the question of how much IS/LM has persisted I had a student do a bibliometric study of the appearance of IS/LM in the EconLit database. ${ }^{4}$ Specifically, he asked how often the term IS/LM appears in articles from 1967 through $2000 .^{5}$ My initial expectation was that the evidence would show that the relative, and perhaps even the absolute, appearance of articles discussing IS/LM would be falling, but that was not the case. As you can see from the graph below, the relative appearance of the term has been increasing over time.

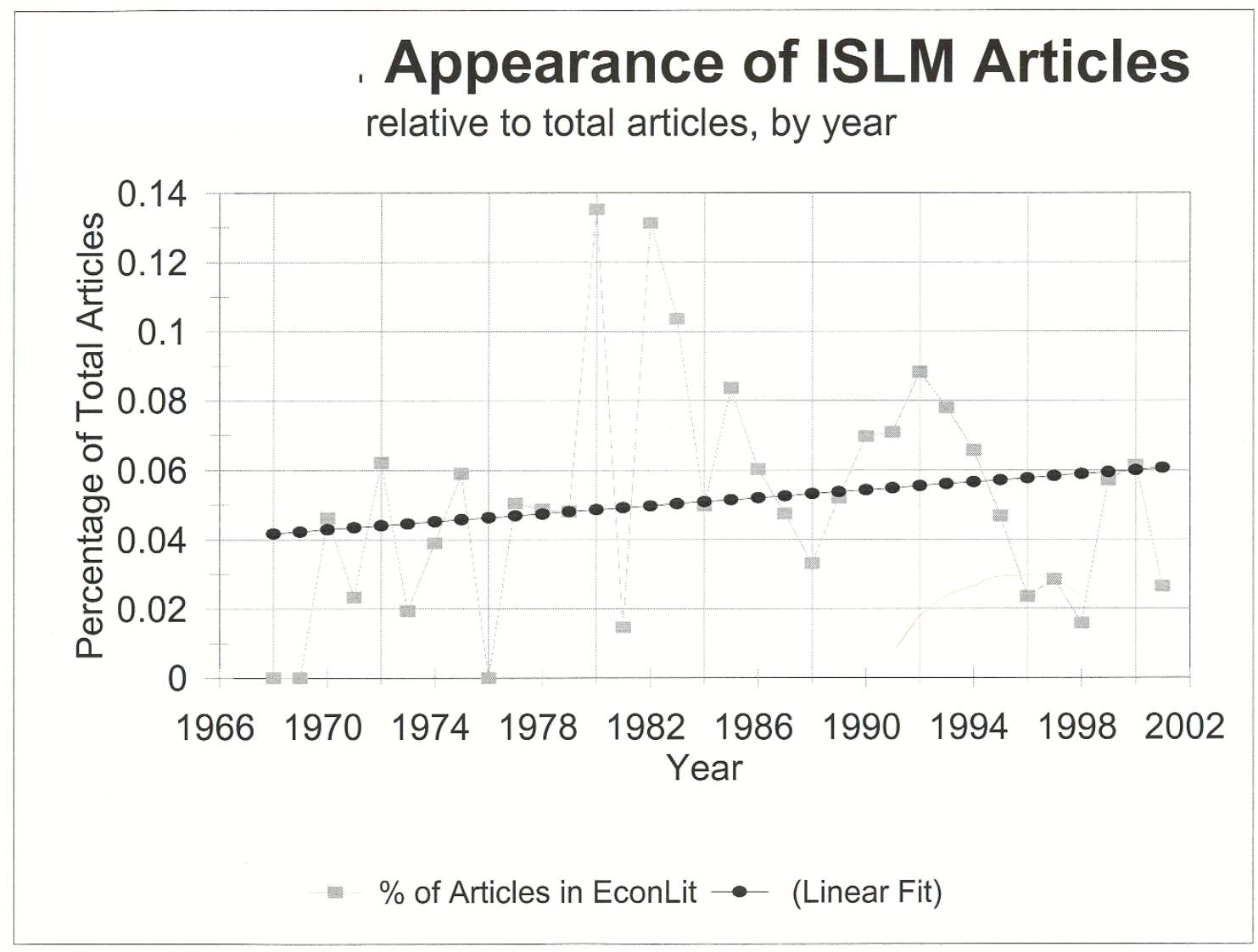

According to this evidence relatively more articles are being published in recent years discussing IS/LM analysis than in earlier years, at least since 1967, which means

\footnotetext{
${ }^{4}$ This section is based upon research done by one of my students, Fred Wyshak (2002) in a paper for my history of economic thought class at Middlebury College.

${ }^{5}$ The database began in 1967 and contains 332,000 articles and over 400 publications. The number has been growing substantially over time, which is why relative frequency is used.
} 


\section{The Strange Persistence of IS/LM}

that in absolute numbers there is a substantial increase in IS/LM articles. ${ }^{6} \mathrm{I}$ am, however, cautious about this evidence because of a technical aspect of the database. The database represents titles and abstracts of articles. More journals now require abstracts, and thus in the relevant period there is likely a bias toward finding the searched-for words in the period's later years than in its earlier years. To test that I had the student look for the relative appearance of the terms "crowding out" and "demand for money," both of which I felt would also be declining. In fact the relative appearance of "crowding out" quadrupled, and the relative appearance of "demand for money" doubled. Since the growth rate of IS/LM articles is substantially below these growth rates, there is reason to believe that the relative number of IS/LM articles has actually decreased, not increased.

While the bibliometric evidence on the number of articles is unclear, it does tell us something about the changing nature of research on IS/LM. The most articles cited appeared in the Journal of Macroeconomics, The Journal of Economic Education, and and Economica Internazionale. Most others appeared in lower-ranked journals. Only four of the journals ranked top-ten today had IS/LM articles over the entire period, and none of these were recent. This suggests that while IS/LM may remain a research topic, it is not part of the modern core, high-level, research.

Looking further at the nature of research on IS/LM, I went through the list of articles and made an informal classification of the articles into four categories: theoretical, empirical, pedagogical, and historical, to see if a trend was readily apparent. The results are presented in Table 1.

Table 1: Percentage of Articles Fitting Various Approaches

\begin{tabular}{|l|l|l|l|l|l|}
\hline Year & Historical & Pedagogical & Theoretical & Empirical & Total \\
\hline $1970-1980$ & 0 & 4 & 23 & 0 & 27 \\
& & $15 \%$ & $85 \%$ & & $100 \%$ \\
\hline $1980-2002$ & 19 & 22 & 52 & 25 & 118 \\
& $16 \%$ & $19 \%$ & $44 \%$ & $21 \%$ & $100 \%$ \\
\hline
\end{tabular}

As you can see from the table, in the period from 1970 to 1980 I classified $85 \%$ of IS/LM articles as theoretical and $15 \%$ as pedagogical. In the post-1981 period the percentage I classified as theoretical declined to $44 \%$, while more articles fell into the historical, pedagogical, and empirical classifications. Also, a significant number of books (not captured in the data base) on the history and pedagogy of IS/LM (for example: Young 1987, Young and Zilberfarb 2000) have been published in the recent period. So it seems that two groups that have played a role in the persistence of IS/LM in the literature are teachers of economics and historians of economic thought.

One surprising finding, shown in the table, is the number of empirical articles on IS/LM in the later period and the lack of empirical articles in the earlier period. Looking

\footnotetext{
${ }^{6}$ The search was of the term IS/LM or variations of it found in the title or abstract of one of the included journals. The occurrences were then divided by the total number of articles for the year, giving the relative occurrence.
} 


\section{The Strange Persistence of IS/LM}

specifically at the titles and occurrences of those empirical articles I found that the large majority of them are in foreign journals that were not included in the earlier-year data base. Almost no IS/LM article classified as empirical appeared in U.S. journals.

My interpretation of this evidence is that core macro theory and empirical work in economics has moved away from the use of IS/LM analysis, but that IS/LM analysis remains a research interest in the history of economic thought (the publication of the articles in this conference likely will make a big impact on the future data), in pedagogy, and in discussions of macro policy issues outside the theoretical core of the profession. So while IS/LM is still around, its role is fundamentally different than its role 40 years ago. The central theoretical debates have moved away from the IS/LM model, but IS/LM's pedagogical role as an organizing structure for nonspecialists to think about macro policy has remained.

\section{The Importance of the Intermediate Macro Course}

The question of the persistence of the IS/LM model is in part a question of why, even as both the lower level and upper level consideration of macro issues change, IS/LM analysis remains in the intermediate macro course and in similar courses at graduate level public policy courses and business school courses.

To answer that question it is necessary to consider what the intermediate macro course is, and is not, designed to do. My first observation is that today the course is not designed to prepare economics majors to go on to graduate study. The reasons are simple. Few majors go on to do graduate work in economics, and many students who take this course are not majors. For example, at Middlebury College, approximately 150-175 students take the course each year and about one of those 175 goes on to graduate work in economics each year. Since only about $60 \%$ of the students who take the course are majors, and none of the non-majors go on, that means that about .3\% of the students taking the course will go on in graduate work in economics. ${ }^{7}$ So the course is not structured for students going into graduate work in economics, but rather for a set of students who are primarily interested in macro policy. The course provides these students with insights into some of the workings of the macro economy, as well as an introduction to the debates about growth policies, monetary and fiscal policy, and the problems of balancing long-run and short-run policy.

The nature of the student body is important because these students are not learning a macro model as a stepping-stone to theoretical or empirical work. They are using IS/LM as a framework - they care little about the problems with it, or its substantial limitations. They want some basic information about policy and institutions, such as what will likely happen to interest rates and income if monetary policy is expansionary. Despite its many problems, the IS/LM model works for these students. It also works for older (over 50) teachers such as me, who were taught macro centered

\footnotetext{
${ }^{7}$ The course is a required course for the international politics and economics major, and a recommended course for a number of other majors. Many of these students will go on to graduate work-some in public policy, others in business or law. But they do not tend to go on to Ph.D. programs in economics.
} 


\section{The Strange Persistence of IS/LM}

around the IS/LM model. This dual support goes a long way toward explaining the persistence of the model in the course.

\section{The Push to Eliminate and Keep IS/LM}

If there is a push to eliminate IS/LM from the intermediate course it comes from new professors fresh out of graduate school who are no longer taught the IS/LM model in graduate school. As graduate students become the teachers, they naturally like to teach what they learn. Thus, there is pressure from younger professors to dump IS/LM analysis and to teach a simplified version of what they have learned in graduate school. As I will discuss below, this pressure has changed the way in which IS/LM is presented in the texts, but has not eliminated it. The reason, in my view, is that the graduate school models students learn are mathematically too sophisticated to present at the intermediate level, and their connection to policy too removed. They require a mathematical sophistication and interest in theory beyond that of most intermediate students. ${ }^{8}$ No easy simplification method exists at the moment, and without one, the material can only be presented heuristically.

This is not to say that modern issues do not show up in the modern texts. Textbooks like to look modern, and textbook authors are always on the lookout for recent developments, new ideas, and discussions to include that make their book look more upto-date than the competition. Open any intermediate text and you will see discussions of credibility, time inconsistency, rational expectations, real business cycles, and inflation targeting. But these discussions are primarily verbal presentations and have not replaced the core IS/LM structure for presentations of monetary and fiscal policy.

Why not structure an economics text with verbal, rather than geometric, presentations? Economists are not trained in verbal analysis, and exams are much easier to structure relative to a specific model that the students can handle. Questions about geometric models have the advantage of being right or wrong, and thus easily tested; since grading is an important aspect of the course, anything that can reduce conflict and make the grading process easier creates pressure to keep it.

As older professors retire and are replaced by younger and differently trained professors, the pressure to eliminate IS/LM will intensify. But I suspect IS/LM will remain. One reason is inertia. A pedagogical model can only be replaced by another pedagogical model. For the intermediate level student IS/LM is a nice pedagogical model; the level of math is about right, so that it challenges students - but not too much. It gives students something to learn that seems to have applications to policy and has, at least in the model, right or wrong answers.

A second pressure to maintain the IS/LM model derives from the fact that it looks similar to a supply and demand model: it has an upward sloping curve and a downward

\footnotetext{
${ }^{8}$ Intermediate books such as Barro (1999), which have tried to present a general equilibrium approach more consistent with that taught in graduate school, have not done well in the market. Barro's book was initially published by a textbook publisher, but it was taken over by MIT Press because sales were below the minimum cutoff of commercial college textbook publishers.
} 


\section{The Strange Persistence of IS/LM}

sloping curve. For some reason this gives students comfort. A third reason is that it provides a nice graphic representations of crowding out, monetary policy, and fiscal policy. A fourth reason is its testability; it provides a wealth of "right or wrong" test questions. A final reason is that its elegance hides much of the underlying reasoning, allowing use of the model without a deep understanding of what does lie beneath. It can be used to talk about policy even if the students do not fully understand the underlying story of interactions of multiple markets being pushed toward equilibrium.

The pressure from younger professors who have not studied IS/LM in graduate school has, however, made a difference in the way IS/LM is presented. Because younger professors are often not familiar with the technical foundations of the curves, the technical presentation of the model has become cursory. Intricacies of dynamics, slopes of curves, or connections of IS/LM issues to earlier debates are no longer presented in the texts, since the younger professors are not trained in them. What this means is that, often, the problems with IS/LM do not become part of what is taught. For example, the fact that the IS curve refers to real interest rates and the LM curve refers to nominal interest rates is seldom discussed. Similarly, the instability of the curves as expectations change, or the problem of interpreting interest rates as differential interest rates of short-term and longterm financial assets, get little discussion. Instead, IS/LM is now presented in an almost mechanistic way; it is a model that shows the effects of monetary and fiscal policy on interest rates and real output.

\section{A Comparison of Two Texts}

One way to see the way in which the presentation of IS/LM analysis has changed is to consider the presentation in the texts back in the 1960s and the presentation in a modern book. In this section I do that, comparing the treatment of the IS/LM model in Ackley's 1961 book with the treatment in Mankiw's 2003 book.

\section{The Ackley Text}

In the 1960s Gardner Ackley's Macroeconomic Theory was the leading book of its day. ${ }^{9}$ The book was 596 pages long, and was seen as accompanying Keynes's General Theory (Ackley writes in the preface that he has his student purchase the General Theory, and that he assigns seven chapters from it. He also states that significant readings from the "vast post-Keynesian literature [are] also assigned." (p. iii) This is consistent with my recollection of the situation in the 1960s; I remember receiving a multiple-page reading list of articles to accompany the text. The list included numerous, fairly recent, articles developing topics that the text discussed. This connection of the text to the literature conveyed the sense, which I believe was the reality at the time, that the text was providing the student an entrée into modern theoretical and policy debates.

The Ackley text is divided into four parts. Part I, Concepts and Measurement, consists of four chapters covering basic concepts, price indices, and national income

\footnotetext{
${ }^{9} \mathrm{I}$ base this discussion on the $3^{\text {rd }}$ printing in 1968 of the 1961 Collier-Macmillan Student Edition. The fact that an edition could exist for 7 years without a major revision is telling both in the way in which the course was stabilized in presentation and the lack of a developed second-hand book market.
} 


\section{The Strange Persistence of IS/LM}

accounting, the later covered in much more depth than it is covered today. The first three chapters in Part II cover Classical macroeconomics, Say's Law, the Quantity theory, full employment equilibrium, the effect of rigid wages, and the savings investment approach to the determination of the rate of interest. The fourth chapter in Part II is a summary that combines the issues discussed in the previous chapters into a model of seven equations, a production function $(y=y(N))$, the profit maximization condition $(\mathrm{dy} / \mathrm{dN}=\mathrm{W} / \mathrm{P})$, the supply of labor $(\mathrm{N}=\mathrm{N}(\mathrm{W} / \mathrm{P}))$ and the quantity theory $(\mathrm{M}=1 \mathrm{Py})$, the savings function $(\mathrm{s}=$ $\mathrm{s}(\mathrm{r}))$, the investment function $(\mathrm{I}=\mathrm{I}(\mathrm{r}))$, and equilibrium in the capital market $(\mathrm{s}=\mathrm{i})(\mathrm{pg}$ 157). These are the key equations in the model, and Ackley states that "a set of equations either identical with or closely resembling these has frequently been used to represent the 'Classical' in contrast to the 'Keynesian'" system." In this chapter he points out that the first four equations are separable from the last three saving/investment equations. He then expands the quantity theory to include the loanable funds theory, which ties the two sets of equations together, at least in the short run. He concludes that chapter with a discussion of how, in "modern macro," fiscal policy is central.

Part III presents Keynesian Macroeconomics. It consists of seven chapters, although the seventh is actually a summary chapter comparing the Classical and Keynesian models. This part begins with a discussion of liquidity preference and how there can be an inconsistency between saving and investment. These issues are presented as qualifications to the Classical model that were first suggested by J.M. Keynes. Finally it discusses wage and price inflexibility, which is presented as part of Classical thought. The next four chapters discuss the consumption function model and the multiplier, which are presented as relevant when there is some constraint preventing the achievement of full employment. The short run, long run, and lags are discussed in these chapters, and there is a fair amount of discussion of empirical evidence. Ackley concludes that the basic Keynesian thesis that consumption is a stable function of income is tentatively accepted. (p. 308)

Chapter 13 is a discussion of multipliers, and an algebraic multiplier model with government is developed. Chapter 14 summarizes the Keynesian model, and is the first and last time the IS/LM model is used. (He calls it the Hicks-Hansen diagram.) In this chapter the IS and LM curves are developed in two ways: by adding a consumption function and speculative demand for money to the Classical model and from the simple Keynesian model, adding the necessary relationships involving wages and prices labor, money and the interest rate. There are a total of three complete IS/LM diagrams in the entire book.

Soon after presenting the IS/LM model Ackley gives an alternative to IS/LM-a four-quadrant diagram, which is similar to diagrams he had used in the presentation of the Classical model. He justifies this alternative model as follows:

The Hicks-Hansen diagram has elegant simplicity that appeals to many. It has the disadvantage, however, that most of the "works" are out of sight. this means that we need to use another diagram (or an extra mental calculation) to determine the effect of a displacement of the equilibrium on the other variables of out system. Likewise, it means that if we wish to 


\section{The Strange Persistence of IS/LM}

consider the effect of a change in some one of the functions which lie behind the IS or LM curve, we need another diagram (or mental process) to determine how the assumed shift will affect the IS or LM curve. Other less elegant apparatus is possible, which exposes more of the relationships to view. (p. 372)

Chapter 15 is the central chapter of the book. It consists of a comparison and evaluation of the Classical and Keynesian models, which are both reduced to a set of equations. (p. 403) The differences between the models are that the Keynesian model has a speculative demand for money, rigid wages, and saving determined by income, whereas savings is determined by interest rate in the Classical model. Later in the chapter he blends the two models together, specifying money as a function of both income and interest rates and saving as a function of both interest rates and income. This leaves the rigid nominal wages in the Keynesian model as the only difference between the Keynesian and Classical models. Chapter 15 is the end of the core presentation, and the remainder of the book, Part IV, covers selected topics such as inflation, investment growth, and the relationship between micro and macro.

\section{The Mankiw Text}

In the early 2000s Greg Mankiw's Macroeconomics is the leading book in the field. The book is 514 pages long, and is divided into six parts. In the preface he states that his four objectives include (1) to balance short-run and long-run issues; (2) to integrate Keynesian and Classical theories; (3) to present macro using a variety of simple models; and (4) to emphasize that macroeconomics is an empirical discipline. These are both similar and different than Ackley's goals. One major difference in the books is that the Keynesian supplement that Ackley mentioned in his preface is not in Mankiw's book, and in many ways, for Mankiw, Keynes is simply a diversion. He writes: "Although Keynes's General Theory provides the foundation for much of our current understanding of economic fluctuations, it is important to remember that Classical economics provides the right answers to many fundamental questions." (p. xxiii)

A second difference is that Mankiw focuses on multiple models that are not combined together into a complete model, whereas Ackley focuses on a single model. The various parts of Ackley's book are meant to lead to the synthesis that is presented in his Chapter 15. Mankiw's book has no grand synthesis. In the introductory chapter he writes, "The field of macroeconomics is like a Swiss army knife - a set of complementary but distinct tools that can be applied in different ways in different circumstances." (p. 11) For Ackley macro was more a single bladed knife, and the chapters are all developing the components of that knife.

Part I in Mankiw consists of only two chapters, and has far less discussion of the broader issues or national income accounting than were found in Ackley. Part II, "Classical Theory: The Economy in the Long Run," is a discussion in which Mankiw states that the economy in the long run involves a time horizon of at least several years. The discussion consists of a chapter presenting a production function, the components of demand, and the general accounting relationships inherent in a general equilibrium model 


\section{The Strange Persistence of IS/LM}

with flexible prices. While the chapter presents a consumption function and a marginal propensity to consume, it makes no use of it in the determination of equilibrium, which instead consists of specifying accounting identities that essentially state that if output remains constant government purchases must crowd out private expenditures. Thus, fiscal policy is presented as altering the allocation of output among alternative uses, not as the central policy tool of macro, as it was in the Ackley book.

Chapter 4 presents the quantity theory and a discussion of inflation. Chapter 5 discusses the open economy issues, such as trade and exchange rates, and their relation to the real economy. Chapter 6 discusses unemployment, focusing primarily on steady state rather than cyclical unemployment. Part III consists of two chapters which present economic growth, starting with the neoclassical growth model, and then progressing up through new growth theory.

Part IV provides the first introduction to the subject that in the large majority of Ackley's book provides the focus - short-run stabilization. It consists of five chapters (Chapters 9-13):Introduction to Economic Fluctuations, Aggregate Demand I, Aggregate Demand II, Aggregate Demand in the Open Economy, and Aggregate Supply. He begins with a presentation of aggregate supply and demand, with aggregate demand determined from the quantity theory with fixed velocity. Aggregate supply is presented as vertical in the long run and horizontal in the short run due to price stickiness. The short-run supply is not related to a production function.

Chapter 10, Aggregate Demand I, presents the foundations of what much of Ackley's book was about. First, the multiplier model is developed in seven pages and then related to the IS curve. The LM curve is then quickly developed from the supply and demand for money. These two curves are then put together as the model that determines the aggregate demand curve (which is a quite different aggregate demand curve than was found in the previous chapter). This new aggregate demand curve, combined with an aggregate supply curve analysis, which he develops in Chapter 13, gives Mankiw a model of aggregate supply and demand, which is his core model for explaining short-run economic fluctuations.

Chapter 11, Aggregate Demand II, uses the IS/LM model to talk about policy, discussing fiscal and monetary policy. The algebra of IS/LM is briefly presented in an appendix. Chapter 12 discusses open economy issues in reference to the IS/LM model for the case of a small open economy where interest rates are set by international markets. Chapter 13 develops three alternative models of aggregate supply. Mankiw does not use any of these models to formally close the system as Ackley did, but instead informally puts them together with an aggregate supply curve to provide a close of the system.

Parts V and VI are devoted to tying up loose ends. Part V discusses macroeconomic policy debates. Chapter 14 raises issues that are being discussed in the current theoretical literature: credibility, time inconsistency, inflation targeting, and rules and discretion. Chapter 15 discusses government debt. Part VI discusses microeconomic foundations to macroeconomics, raising issues in consumption, investment, money supply and demand, and advances in business cycle theory. 


\section{Differing Treatments of the IS/LM Model}

As should be clear from the above discussion, there are substantial differences in the way Ackley and Mankiw use the IS/LM model. In Ackley IS/LM is an elegant summary of what he has presented before. While IS/LM is used as the model, much of the presentation is about the development and thinking behind that model. It is the ideas behind IS/LM, not the model itself, that Ackley is interested in. He even states that a problem with the IS/LM model is that it hides important elements of the reasoning. Ackley did not give IS/LM very much focus because, in its elegance, it tended to hide the ideas that he considers the most important. Consistent with this use of IS/LM, there is no entry in the index for IS/LM or its components, and there are only three complete IS/LM diagrams in the entire book. IS/LM appears in only one chapter of the book even though the majority of the book is about the short run, and there it is supplemented by an alternative geometric exposition that "exposes more of the relationships to view." (p. 372)

For Mankiw, IS/LM serves a fundamentally different role. It is not meant to synthesize the ideas he has presented earlier, but instead is a subsidiary model of the AS/AD model that is useful for handling discussions of monetary and fiscal policy with a fixed price level. But, ironically, in this new role IS/LM gains prominence. Instead of being relegated to one chapter, as it is in Ackley, it shows up significantly in three chapters. The IS curve, the LM curve, and the IS/LM model all have significant entries in the index, and there are 28 complete IS/LM diagrams compared to the three in Ackley. This is the case even though Mankiw gives much less focus to short-run stabilization issues than did Ackley.

Summarizing: In Ackley IS/LM is simply a minor expositional tool used as one means of conveying multimarket equilibrium and the components that built it up are discussed at length. The ideas behind the model, not the model, are what is important. For Mankiw, and for modern texts generally, far less discussion goes to the components of IS/LM. Instead, the IS/LM model becomes primarily a tool for discussing policy.

This change in the use of IS/LM reflects the change in the goal of the intermediate course discussed above. Ackley's text was designed for a much more consciously theoretical course in which learning the model connected the reader to the modern theoretical literature. Hence its title: Macroeconomic Theory. That is not the case with Mankiw's text. Since the upper level macro theory is far less unified, he presents multiple models, and does not tie them together in a grand synthesis model. Hence his text (and most other modern intermediate macro texts) are no longer called Macroeconomic Theory, but is simply called Macroeconomics. In modern books, the IS/LM model is not used to connect to the theoretical literature, but is instead used a convenient focus for the discussion of short run policy. Because the modern course focuses heavily on policy, ironically, that means that the IS/LM model is given more, not less emphasis in Mankiw.

Recognizing this difference suggests that we must be clear about what aspect of IS/LM analysis is persisting. The theoretical focus on the analysis of the goods and the money (and the hidden bond market) that underlies the individual curves has not 


\section{The Strange Persistence of IS/LM}

persisted. That discussion, while still there, has been significantly reduced. What has persisted is the particular graphical technique of looking at multi market equilibrium in equilibrium space, and using the curves in that model to discuss monetary and fiscal policy. Today, one does not see the four-quadrant diagram in any major intermediate macro text, but one sees the IS/LM diagram in every one of them.

The way in which the IS/LM model is used today suggests that one of the reasons that the particular IS/LM graphical technique is so persistent is that its elegance allows it to be used in a rough and ready fashion, in which the underlying model is less important than whether some underlying model exists that gives one the upward and downward sloping curves one needs to close the model and determine equilibrium. If correct, this suggests that IS/LM has remained central to the teaching of macroeconomics because of its chameleon nature which has allowed it to evolve from a simplified description of the model economists thought described the economy - a simplified econometric model — to a pedagogical crutch which is not descriptive of theory-but is instead a convenient totem on which to hang discussions of monetary policy, fiscal policy, and their interactions.

Its elegance allows a clouding over of the theoretical issues and underpinnings of the model. I suspect that it is for that same reason that the AS/AD model has gained such wide acceptance at the introductory level. With IS/LM you've got an upward sloping curve, and downward sloping curve, and you can do exercises involving shifts in both curves and the effects of various monetary and fiscal policies.

\section{IS/LM in the Future}

The future of IS/LM is very much tied to the future of macro. Because of its chameleon-like nature and ambiguous elegance, it can continue to exist in a variety of alternative scenarios, but not in all. Perhaps the most fertile environment for IS/LM is the one I believe most likely in the near term - an environment in which economists generally accept that IS/LM is loosely consistent with a dynamic general equilibrium model, and that, given appropriate nominal rigidities, an inverse relationship between short- run goods market equilibrium and real interest rates is possible. Add to that an assumption that monetary authorities can choose a real interest rate in the short run, and one has a foundation for an IS/LM type model. Within that environment the future of IS/LM as a pedagogical device for rough and ready discussions of stabilization policy seems assured, not because of its strength, but because of the lack of an alternative.

In the more distant future I see macro coalescing as a field whose foundation is in the study of complex systems. By that I mean that macro variables will be seen as following from interrelationships that include nonlinear dynamic relationships. These complex relationships make noncontextual micro foundations for the curves impossible to derive. The reason is that these microeconomic foundations have such complex interrelationships that they are analytically intractable. If this change takes place, it will mean bring with it a significant change in the way macro problems and policy to thought about. Instead of macro theory being the study of infinitely bright individuals operating in 


\section{The Strange Persistence of IS/LM}

an information-rich environment as it is now, it will become the study of reasonably bright and adaptable individuals operating in information-poor environments.

This change in focus will have significant effects on the way we see macro phenomena relating to theory. In large part the study of macro relationships will turn to study of sophisticated statistical techniques that will search for possibly exploitable, temporary patterns in the data, and to agent-based simulations that will relate the patterns to broad general deductive laws--such as the law of one price - that loosely underlie our general analytic understanding of the economy. This alternative approach will eliminate the standard analytic foundation for the IS/LM model, as well as the new dynamic general equilibrium approach with nominal rigidities foundation, but, as I have suggested in Colander (2000), it will not necessarily eliminate the IS/LM model, since, even in this framework, it is still possible to view the IS/LM model as capturing temporary patterns. The difference is that IS/LM will become an historical model expressing first order changes in variables that are centered on the existing institutional base; it will not be an independent model of the entire economy outside of an institutional context. The equilibrium it determines is only in reference to an historically determined starting point.

While it is possible for IS/LM to remain in this complex system future for IS/LM, it is, in my view unlikely. As the work in macro becomes more dependent on data extraction and agent-based simulation, the pedagogy of macro will change. It will focus more and more on standard simulations and statistical techniques that pull information from data. As it does so, the teaching of it will move from the printed page to the computer where dynamic models and simulations will be the standard techniques. Within this computer environment the two-dimensional elegance of IS/LM will no longer be a virtue, and IS/LM will fade away, along with the intermediate macro texts that gave it its lifeblood. 


\section{Bibliography}

Ackley, Gardner. Macroeconomic Theory. New York: Macmillan Company. 1961 (Collier-Macmillan Student Edition, third printing, 1968).

Barro, Robert. Macroeconomics (5th ed.) Boston, MA: MIT Press. 1998.

Clarida, Jordi Gali, and Mark Gertler. "The Science of Monetary Policy: A New Keynesian Perspective.” Journal of Economic Literature. December 1999.

Colander, David. "Post Walrasian Macroeconomics and IS/LM Analysis." In Young, Warren and Ben Zion Zilberfarb. IS-LM and Modern Macroeconomics. Boston and London: Kluwer Academic Publishers. 2000.

Colander, David and Edward Gamber. Macroeconomics. Upper Saddle River, New Jersey: Prentice Hall. 2002.

Foley, Duncan. "Interview." In Colander, David, Barkley Rosser and Richard Holt. The Changing Face of Economics: Interviews with Cutting Edge Economists. Manuscript in preparation.

Klein, Lawrence. "The IS-LM Model: Its Role in Macroeconomics." In Young, Warren and Ben Zion Zilberfarb. IS-LM and Modern Macroeconomics. Boston and London: Kluwer Academic Publishers. 2000.

Mankiw, Gregory. Macroeconomics. New York: Worth Publishers. 2003

Solow, Robert. "Mr. Hicks and the Classics" Oxford Economic Papers (vol. 36. Supplement). 1984.

Taylor, John and Michael Woodford. Handbook of Macroeconomics. North Holland: Amsterdam. 1999.

Tobin, James. Asset Accumulation and Economics Activity. Oxford: Basil Blackwell. 1980.

Wychak, Fred. "IS-LM in the Economics Literature." Unpublished Middlebury College paper. 2002.

Young, Warren and Ben Zion Zilberfarb. IS-LM and Modern Macroeconomics. Boston and London: Kluwer Academic Publishers. 2000.

Young, Warren. Interpreting Mr. Keynes: The IS-LM Enigma. Cambridge: Polity Press. 1987.

Yun, Tack. "Nominal Price Rigidity, Money Supply Endogeneity, and Business Cycles." Journal of Monetary Economics. 1996. 